\title{
AUDITORY FUNCTION IN A GROUP OF ADULTS INFECTED WITH HIV/AIDS IN GAUTENG, SOUTH AFRICA
}

\author{
KATIJAH KHOZA \& ELEANOR ROSS
}

Department of Speech Pathology and Audiology

University of the Witwatersrand

\begin{abstract}
Numerous international studies have demonstrated a relationship between HIV/AIDS and auditory function. The aim of this study was to explore this relationship in a group of adults infected with HIV/AIDS attending an outpatient clinic in a hospital located in Gauteng, South Africa. The prevalence of hearing loss; the type, degree and configuration of the hearing loss; the relationship between the hearing symptoms and the progressive stages of the disease, and the type of onset of hearing problems were examined. The results of the study indicated a prevalence rate of hearing loss which was as high as $23 \%$ in the sample surveyed. The types of hearing loss included conductive and sensorineural, while the degree of severity ranged from slight to profound in nature. The configuration of the hearing loss was not frequency-range-specific, and the degree of severity did not seem to worsen with the progression of the HIV/AIDS disease. However, there did seem to be an increase in the occurrence of sensorineural hearing loss with the deterioration of patients' immunological status. Analysis of patients' audiological results along with their case history data suggested that their hearing loss may have been caused by opportunistic infections and/or their treatments. These results are discussed in terms of their implications for the clinical management of patients with HIV/AIDS; education of team members; and policy formulation.
\end{abstract}

Key Words: Immune cell count; AIDS; Ototoxic; Serology; Hearing loss

\section{INTRODUCTION}

The acquired immune deficiency syndrome (AIDS) and the Human Immunodeficiency Virus (HIV) that causes it seem to have arguably created more challenges to science and medicine than any other single disease. Moreover, the AIDS epidemic is now in its third decade and would seem to have become one of the most important public health problems in South Africa (South African Department of Health, 2000).

HIV is reported to cause a total breakdown of the body's natural immune system by reducing the immune cell count (Bankaitis, 1996). Such a reduction leads to the development 'of various diseases, which does not occur similarly in all patients infected with the virus. Bankaitis (1996) reports that many of the patients with the virus remain. asymptomatic and maintain normal immune cell count for long periods of time, and they are therefore described as falling outside the documented clinical definition of AIDS. For patients to be diagnosed with AIDS, they must either have an extremely low Thelper lymphocyte count or a CD4+ blood count (below $200 / \mathrm{mm}^{3}$ of blood) or present with at least one AIDSdefining condition. The American Center for Disease Control and Prevention (CDC) classifies HIV infected patients into three distinct groups according to their CD4+ blood count, where patients with CD4+ count greater than $500 / \mathrm{mm}^{3}$ are classified as asymptomatic (Stage 1), patients with' CD4+ count between 200 and $499 / \mathrm{mm}^{3}$ as symptomatic (Stage 2), and patients with CD4+ count less than $200 / \mathrm{mm}^{3}$ as having full blown
AIDS (Śtage 3) (Bankaitis, '1996; Chandrasekhar, Connelly, Brahmbhatt, Shah, Kloser, \& Baredes, 2000).

From the first diagnosis of HIV/AIDS and throughout most of the epidemic the concern of most people has been to sustain life by preserving the immune system and fighting off primary, life-threatening infections. However, as a result of recent advances in treatment, the focus of therapy has shifted to a more rehabilitative approach with the emphasis on enhancing quality of life (Friedman \& Noffsinger, 1998). In addition to treating life-threatening infections there is an increasing awareness of the need to consider the impact of HIV/AIDS on cognitive, motor, and sensory domains, with hearing changes being a potential presentation at any stage of the disease (Larson, 1998).

As early as 1987 Sooy reported on abnormal audiologic findings of thresholds worse than $25 \mathrm{~dB} \mathrm{HL}$, with a high frequency sloping configuration on pure tone audiometry in patients with AIDS. More recently, a study of black female HIV positive patients in a South African hospital reported that the most prevalent degree and type of hearing loss found was slight to mild and sensorineural in nature (Fuzani, 1999). Chandrasekhar et al. (2000) reported that the high frequencies of $4000 \mathrm{~Hz}$ and 8000 $\mathrm{Hz}$ were significantly elevated relative to other frequencies. Such results are in line with those reported by Sooy (1987) that indicate worsening hearing loss in high frequencies.

With regard to otologic symptoms, contradictory research findings, mostly from American studies, have been reported. For example, Rosenberg, Schneider, and 
Cohen (1985) reported a total absence of otologic symptoms in American patients who presented with head and neck manifestations of the disease, while Booth (1997) noted an increasing trend in the number of people living with HIV/AIDS who presented with otologic symptoms. Lalwani and Sooy (1992) maintained that ear related manifestations of HIV/AIDS occur to a lesser degree relative to other head and neck complaints. These discrepancies in findings could be attributed to different methodological steps employed in these studies.

The management of HIV/AIDS, which involves medications such as Azidothymidine (AZT) and radiation treatment, has been reported to have an adverse effect on the auditory function of individuals infected with HIV/AIDS (Bankaitis \& Larson, 1998; Schount7, 1998). However, more recently, Chandrasekhar et al. (2000) reported that the sensorineural hearing loss detected in their outpatient subjects did not correlate with their routine HIV/AIDS medications used. Despite these contradictory findings, changes in audiological function attributable to HIV/AIDS, and the medications used to treat the condition and its associated opportunistic infections, are likely to increase the demand for audiologists to work with patients with HIV/AIDS.

Whilst it is evident that a cure for AIDS does not appear to be imminent, treatment strategies have been improving rapidly suggesting that long-term therapeutic protocols for the management of infections are likely to be developed in the near future (Tshabalala-Msimang, 1999). Regensberg and Maartens (1999) stated that the drugs currently available have significantly improved the prognosis and quality of life for patients living with HIV/AIDS thereby allowing them to continue to be productive members of society. Improved hearing and enhanced communication have the potential of contributing positively to the patients' quality of life, and hence ensuring their ability to remain productive members of society.

While hearing loss related to HIV/AIDS is receiving increasing attention in the international literature, the reported prevalence rates may not necessarily apply to South Africa. İn view of the increase in the number of South Africans who are reported to be infected (South African Department of Heath, 2000), as well as the researcher's clinical experience, and review of audiology records of patients with HIV/AIDS at the research site, it was hypothesized that hearing loss might be the presenting problem in some cases of undiagnosed HIV infection. Real, Thomas, and Gerwins (1987) support the hypothesis that sensorineural hearing loss may in some cases be the presenting complaint of undiagnosed HIV infection.

Furthermore, because the head and neck region has been reported as a common anatomical site for medical conditions associated with HIV/AIDS (Rosenberg et al., 1985), audiologists, as part of the head and neck team, need to contribute to the theoretical knowledge about audiological manifestations of HIV/AIDS. Such knowledge may increase the likelihood of appropriate assessments leading to accurate diagnoses and management (Noffsinger \& Friedman, 1996). For these reasons, this study was conducted.

\section{METHODOLOGY AIM OF THE STUDY}

The aim of the study was to explore the auditory function in a group of adults infected with HIV/AIDS attending a hospital outpatient clinic in Gauteng, South Africa. The six specific sub-aims were to determine the prevalence of hearing loss in the sample; to assess the type, degree, configuration and symmetry of the hearing loss; to determine the relationship between the hearing symptoms and the progressive stages of HIV/AIDS; to explore the nature of onset of hearing loss (e.g. sudden vs. gradual/progressive onset); to determine the relationship between the nature of onset of sensorineural hearing loss and the severity of the hearing loss; and lastly, to relate the HIV/AIDS signs and symptoms of each subject to the nature of the hearing loss.

\section{RESEARCH DESIGN}

The study was exploratory in nature. The design utilised was non-experimental and observational in nature with no control group and non-randomization of subjects (McCall, 1990). The aim was to determine whether there was a relationship between HIV/AIDS and auditory function. The subjects' age, clinical stage of the HIV/AIDS, and co-occurring diseases (e.g. TB, Syphilis, middle ear pathology) were the independent variables, while the audiological measures (otoscopy, impedance audiometry, pure tone audiometry, ABR) were the dependent variables.

\section{DESCRIPTION OF SUBJECTS}

\section{Subject Selection Criteria}

The South African population that is predominantly infected with HIV/AIDS is unique in that it includes mineworkers (who are exposed to noise in the workplace), and HIV/AIDS co-occurs with diseases such as TB and Syphilis (South African Department of Health; 2000). The treatment of HIV/AIDS, the opportunistic infections and co-occurring symptoms may impact on hearing (Bankaitis \& Schountz, 1998; Larson, 1998). It was therefore difficult to specify selection criteria without excluding almost all patients attending the HIV/AIDS clinic. As this was an exploratory study which endeavoured to représent the South African HIV/AIDS population, it was considered undesirable to isolate the impact of HIV/AIDS on hearing. Such a sampling procedure has disadvantages relating to the presence of confounding variables e.g. ototoxic drugs for TB, noise exposure, syphilis, etc. However, inclusion and documentation of such variables in the HIV/AIDS population might yield important information.

Consequently, the subject selection criteria were:

$>\quad$ Subjects' HIV/AIDS status needed to have been confirmed by serology studies.

$>\quad$ Subjects needed to be between the ages of 18 and 55 years. There are reportéd age différences in presentation of the virus (Matkin, Diefendorf, \& Erenbérg, 1998).

$>$ Subjects were not to have presbycusis. Presbycusis could confound the results since it also presents as a sloping high frequency sensori-neural hearing loss ' (SNHL) (Katz, 1994). 
$>\quad$ The subjects had to be alert, oriented, able to provide informed consent, and to participate in an audiological assessment.

\section{Sampling Procedure}

A convenience sampling technique was utilised in recruiting subjects for the study. Subjects volunteered to have their hearing status evaluated in response to notices that were posted at the HIV/AIDS clinic inviting them to participate in the study, and in response to the researcher's verbal explanations of the purpose of the project at this clinic.

\section{Subject Description}

A total of 150 subjects, including both males and females, comprised the research sample. A profile of the subjects is set out in Table 1 .
The subjects spanned all three CDC stages and were also categorised into four age groups as depicted in Table 1. Inspection of the subjects' data revealed demographic similarities between them and the general South African population infected with HIV/AIDS (Crewe, 1999; Tshabalala-Msimang, 1999). Firstly, Crewe (1999), supported by Tshabalala-Msimang (1999) maintains that women have the highest HIV prevalence rates in the country. The gender bias in the prevalence rates of the disease was also evident in this sample, with a much higher number of participants in the study being female. Secondly, the distribution of subjects across the different age ranges mirrors those of the country. Most subjects were between 20 and 45 years of age, which is the most vulnerable age group for HIV/AIDS (Tshabalala-Msimang, 1999).

Table 1. Demographic and medical profile of all subjects in the study $(N=150)$

\begin{tabular}{|c|c|c|}
\hline Factor & Sub-Category & Number \\
\hline $\begin{array}{c}\text { Age Ranges (Years) } \\
\therefore\end{array}$ & $\begin{array}{l}18-25 \\
26-35 \\
36-45 \\
46-55 \\
\end{array}$ & $\begin{array}{l}19 \\
77 \\
45 \\
9\end{array}$ \\
\hline Gender & $\begin{array}{l}\text { Male } \\
\text { Female }\end{array}$ & $\begin{array}{l}54 \\
96 \\
\end{array}$ \\
\hline Ethnic Group & $\begin{array}{l}\text { Black } \\
\text { White } \\
\text { Coloured } \\
\text { Indian }\end{array}$ & $\begin{array}{l}147 \\
2 \\
1 \\
0\end{array}$ \\
\hline $\begin{array}{l}\text { CD4+ Count }\left(/ \mathrm{mm}^{3}\right) \\
\text { (CDC Stages) }\end{array}$ & $\begin{array}{l}\text { Asymptomatic (Stage 1) }>500 / \mathrm{mm}^{3} \\
\text { Symptomatic (Stage 2) } 200-499 / \mathrm{mm}^{3} \\
\text { AIDS (Stage 3) }<200 / \mathrm{mm}^{3}\end{array}$ & $\begin{array}{l}(25 \%) \\
(35 \%) \\
(40 \%) \\
\end{array}$ \\
\hline Hearing Status. & $\begin{aligned} & \text { Normal: } \text { Stage 1 } \\
& \text { Stage } 2 \\
& \text { Stage } 3 \\
& \text { Abnormal: Stage } 1 \\
& \text { Stage 2 } \\
& \text { Stage 3 } \\
&\end{aligned}$ & $\begin{array}{ll}\text { Total: } 115 & (77 \%) \\
\text { Total: } 35 \quad(23 \%)\end{array}$ \\
\hline Tinnitus & $\begin{array}{l}\text { Present } \\
\text { Absent }\end{array}$ & $\begin{array}{ll}34 & (23 \%) \\
116 & (77 \%) \\
\end{array}$ \\
\hline \begin{tabular}{l|l} 
Vertigo & $\vdots$ \\
\end{tabular} & $\begin{array}{l}\text { Present } \\
\text { Absent }\end{array}$ & $\begin{array}{ll}14 & (9 \%) \\
136 & (91 \%)\end{array}$ \\
\hline $\begin{array}{l}\text { Symmetry of hearing loss } \\
(\mathrm{n}=35)\end{array}$ & $\begin{array}{l}\text { Unilateral } \\
\text { Bilateral }\end{array}$ & $\begin{array}{ll}10 & (29 \%) \\
25 & (71 \%) \\
\end{array}$ \\
\hline Type of onset of hearing loss & $\begin{array}{l}\text { Sudden } \\
\text { Gradual }\end{array}$ & $\begin{array}{l}16 \\
19 \\
\end{array}$ \\
\hline $\begin{array}{l}\text { Type of hearing loss } \\
\cdot\end{array}$ & $\begin{array}{l}\text { Conductive } \\
\text { Sensorineural } \\
\text { Mixed }\end{array}$ & $\begin{array}{l}4 \\
21 \\
10\end{array}$ \\
\hline $\begin{array}{l}\text { Possible aetiology of hearing } \\
\text { loss }\end{array}$ & $\begin{array}{l}\text { Meningitis } \\
\text { Oto/syphilis } \\
\text { Otitis media } \\
\text { Encephalitis } \\
\text { TB treatment }\end{array}$ & $\begin{array}{ll}9 & \\
13 & \\
14 \\
1 \\
2 & \\
\end{array}$ \\
\hline $\begin{array}{l}\text { Hearing status and possible } \\
\text { aetiological factors } \cdot \\
. \because\end{array}$ & $\begin{array}{l}\text { Subjects with possible causal factors (i.e. } \\
\text { TB, syphilis) but normal hearing } \\
(\mathrm{N}=115) \\
\text { Subjects with possible causal factors and } \\
\text { abnormal hearing }(\mathrm{N}=35)\end{array}$ & $\begin{array}{l}14 \quad(12 \%) \\
\text { (14 of the } 115 \text { subjects with normal } \\
\text { hearing) } \\
32 \quad(91,42 \%) \\
(32 \text { of the } 35 \text { subjects with hearing } \\
\text { loss) }\end{array}$ \\
\hline Noise exposure $\cdot \quad \therefore$ & $\begin{array}{l}\text { Present } \\
\text { Absent } \\
\end{array}$ & $\begin{array}{lll}23 & (15 \%) \\
127 & (85 \%) \\
\end{array}$ \\
\hline
\end{tabular}




\section{TESTING PROCEDURES}

The testing procedure was conducted in four phases:

\section{Phase I}

Prior to commencement of the study, permission to conduct the research project was obtained from the University of the Witwatersrand Medical Ethics Committee for Research on Human Subjects, the Hospital Superintendent and relevant Heads of Departments. Thereafter, the researcher discussed details regarding the project with the medical team at the HIV/AIDS clinic, and enlisted their co-operation in informing their patients about the study. Informed consent was obtained from all individuals volunteering to participate in the study.

A case history form (available on request from researchers) was used to record the case history, audiological data, and medical variables that could have an impact on the results of the study.

\section{Case History Form}

The devised case history form consisted of the following sections:

$>$ Demographic information: Information obtained included subjects' ethnic group, age and gender and was used to determine the representative nature of the sample.

$>$ History of noise exposure: Information on noise exposure was obtained to differentiate between hearing loss that was noise-induced versus HIV/AIDS related. The data gathered included the length of time the subject was exposed to noise, the type of noise, and the intensity of the noise as per subjects' report. Chronic and consistent exposure to noise causes hearing loss particularly in the high frequencies, generally seen as a dip at $4000 \mathrm{~Hz}$ (Katz, 1994).

$>$ History of tinnitus and vertigo: Tinnitus and vertigo are associated with hearing loss (Katz, 1994), and the subjects were asked if they experienced these symptoms which were described by the researcher.

$>$ Hearing status: Information on family history of hearing impairment, previous audiologic assessments, time since onset and nature (sudden, gradual) of onset, progression of the hearing loss, current hearing status, and laterality of the hearing loss was obtained from subjects. Such questions form part of the audiologic evaluation (Bess \& Humes, 1990; Schuknecht, 1993).

$>$ Medical history: The subjects' medical records were reviewed to obtain information on the following:

- The clinical or serological evidence of syphilis as this disease is known to cause hearing loss (Darmstadt \& Harris, 1989).

- Case history factors that may have contributed to a hearing loss e.g. history of prior ear disease; head trauma; use of ototoxic drugs; diseases such as TB, Cancer, etc. (Katz, 1994; Lalwani \& Sooy, 1992).

- Treatment history that could contribute to hearing loss. Two major forms of such treatment are radiation therapy and AZT (Bankaitis \& Schountz, 1998; Larson, 1998).
- The different CDC categories (asymptomatic stage; symptomatic stage; and full-blown AIDS) (Bankaitis, 1996).

Case history information was obtained by interviewing each subject prior to the audiologic evaluation. Individuals who were literate in English completed parts of the case history form (except for the medical information) on their own. The medical history information (e.g. medical diagnosis, serology information, CD4+ count, ENT diagnosis, etc) was obtained from the medical records for all subjects.

\section{Phase II}

Following infection control measures proposed by Kemp and Roeser (1998), basic audiological information was obtained via otoscopy, tympanometry, and pure tone audiometry for each subject. Hearing thresholds were obtained by both air conduction and bone conduction so as to differentiate between conductive and sensorineural hearing loss as per Katz's protocol (1994).

The objective of the otoscopic evaluation, using a Welch Allyn otoscope, was to examine the subjects' ears for the presence of impacted wax, otitis externa, possible otitis media, perforated tympanic membranes, collapsed ear canals, presence of any growths and so forth (Friedman \& Amold, 1993). Findings were then confirmed by the Otolaryngologists at the hospital.

Impedance audiometry in the form of tympanometry assessed the status and integrity of middle ear functioning. Tympanometry has been reported to be superior to routine otoscopy in correctly predicting the absence or presence of middle ear effusions (Silman \& Silverman, 1991). The use of both assessment procedures in a complementary fashion was deemed necessary for this study as the results were combined to provide valuable redundant information to facilitate accurate diagnoses (Wiley \& Fowler, 1997).

\section{Phase III}

Auditory Brainstem Response (ABR) measurements were obtained for subjects with sensorineural hearing loss (SNHL) in order to determine possible retrocochlear involvement (Hall, 1992; Hood, 1998). It was acknowledged that the ABR should be used in a test battery approach rather than in isolation to determine site of auditory pathology. The test battery includes Otoacoustic Emissions, Speech Discrimination measures, Loudness Balance tests, Metz test-Acoustic Reflex, Short Increment Sensitivity Index, Tone Decay, and Acoustic Reflex decay (Katz, 1994). However, these site of lesion tests were not performed because of the lack of appropriate testing tools at the time of the study. Therefore the ABR, which has been documented as án objective and sensitive tool for assessing the neural intergrity of the auditory pathway was utilised (Hall, 1992; Hood, 1998). Hall's (1992) protocol was'adopted for ABR testing for neurodiagnosis of eighth nerve or auditory brainstem dysfunction. Responses - were collected three times for each ear so as to ensure reliability of the measurement procedures and that the artefacts were of acceptable levels. The criteria for determining abnormal ABR were those advocated by Hall (1992), Hood (1998), Silman and Silverman (1991), and Spehlmann (1985). 
Speech testing was not one of the tests selected to form part of the test battery due to the paucity of standardised word lists for the multilingual South African population. In addition, it was envisaged that there could be poor performance on speech tests because of differences in dialect, word-meaning, and word familiarity levels. Such problems have been reported by Wilson, Jones, and Fridjhon (1998) who maintained that subjects' educational level may influence their linguistic performance.

\section{Phase IV}

This phase involved re-inspection of the data for the subgroup with abnormal hearing. All persons whose hearing loss was not directly attributable to HIV/AIDS, but rather to confounding variables such as ototoxicity and diseases such as meningitis were excluded. The purpose of this exercise was to try to establish the number of subjects where there might be a direct link between HIV/AIDS and impaired hearing function.

\section{DATA ANALYSIS ' AND STATISTICAL PROCEDURES}

Following consultations with statisticians it was concluded that the nature of the data collected precluded inferential statistical analysis, and therefore descriptive statistical analyses were performed.

Each subject was classified as either having normal or abnormal hearing following the audiological evaluation. Normal hearing was regarded as responses at and better than $25 \mathrm{~dB}$ HL, with abnormal results being thresholds worse than 25dB HL (Katz, 1994; Silman \& Silverman, 1991). The degree of hearing loss was determined using Silman and Silverman's (1991) classification of "Magnitude of Hearing Impairment". This classification system, supported by Katz (1994), advocates that impaired hearing function begins at an average hearing level of $25 \mathrm{~dB}$. HL. Abnormal hearing was further categorized/into type of hearing loss;

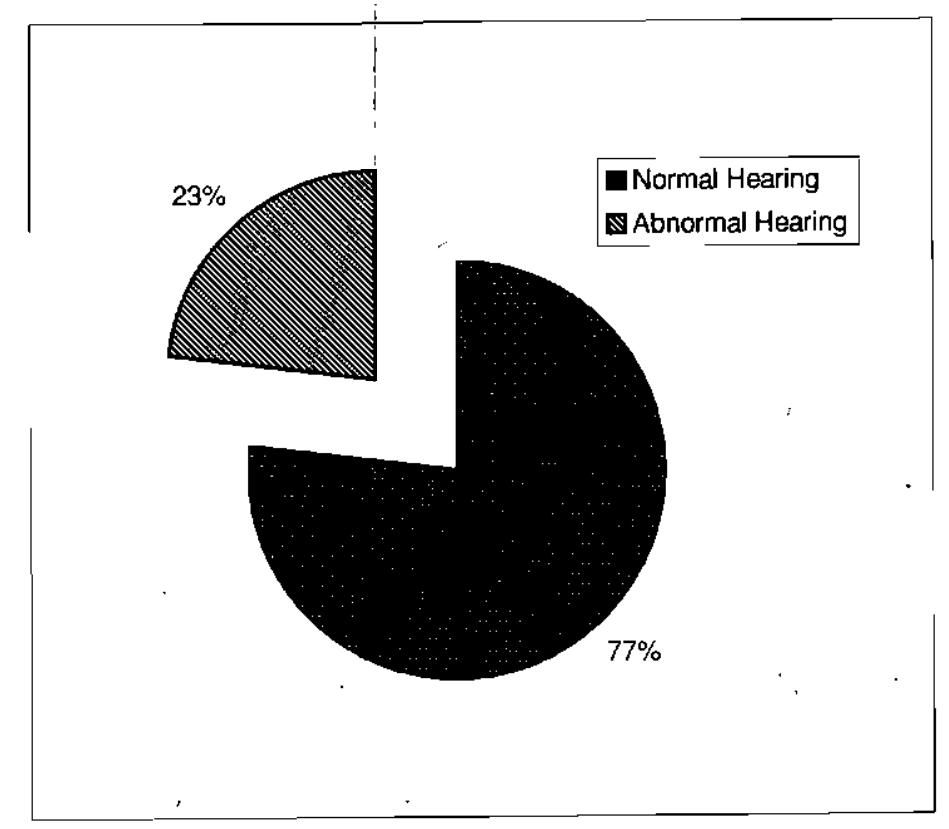

Figure 1: The prevalence of hearing loss in HIV/AIDS subjects

(n= 150)

Die Suid-Afrikaanse Tydskrif vir Kommunikasieafwykings, Vol. 49, 2002 severity; and the nature of onset of the hearing loss. All case history factors were :recorded and analysed along with the audiological results in order to obtain a comprehensive evaluation. The abnormal hearing. results were then group matched to the different CDC stages to determine relationships between hearing loss and stages of HIV/AIDS. Furthermore, the data were examined to establish if there was any relationship between the nature of onset (sudden or gradual) of SNHL and the severity of the hearing loss.

\section{RESULTS AND DISCUSSION}

According to the research literature, auditory abnormalities have been reported in persons with varying degrees of HIV infection, in both symptomatic and asymptomatic patients (Bankaitis \& Keith, 1995; Bankaitis, 1996; Chandrasekhar et al., 2000; Fuzani, 1999). Similar findings were obtained in the present study and have particular relevance to the field of audiology. The results are discussed in accordance with the sub-aims of the study.

\section{The prevalence of hearing loss}

Of the 150 subjects tested, $115(77 \%)$ had normal hearing, and $35(23 \%)$ presented with a hearing loss as depicted in Figure 1. Thus $23 \%$ of subjects had both otologic and audiological symptoms that included tinnitus, vertigo, and hearing losses with varying nature and severity. These results appear to be consistent with some internationally published studies on otologic and audiologic manifestations of HIV/AIDS (Bankaitis, 1996; Bankaitis \& Keith, 1995; Birchall et al, 1992; Chandrasekhar et al, 2000). The general trend reported in the American literature suggests that the prevalence of otologic manifestations of HIV/AIDS is relatively small (Sooy, 1987), with the exception of Flower (1991) who reported auditory abnormality prevalence rates in adults with AIDS to be as high as $75 \%$. This difference in results could be related to variations in subject selection criteria, sample sizes, and the otologic versus audiologic nature of the studies.

More recently, Booth (1997) reported an increase, in the United States, in the number of patients with otologic symptoms associated with AIDS. Birchall, Wight, French, and Smith (1992) reported hearing loss (not type-specific) on pure tone testing in $39 \%$ of patients who were HIVpositive and syphilis-negative with no neurological symptoms, while Sooy (1987) described hearing impaiment greater than $25 \mathrm{~dB} \mathrm{HL}$ on pure tone testing in $49 \%$ of the subjects. A surprising finding was that in the presence of these abnormal audiologic findings in Sooy's study, the speech discrimination scores were reported to have consistently been above $82 \%$ for all patients evaluated, with the majority of the patients obtaining scores that were better than $90 \%$.

Consistent with the aforementioned studies, the current study also reported the presence of otologic disease in some subjects who presented with head and neck symptoms. However, this finding differs from those studies (Marcusen \& Sooy, 1985; Rosenberg et al, 1985) reporting a total absence of otologic signs in the adult population. 
These studies concluded that while there was an extremely low incidence of otologic disease in adults, there was a much higher incidence in the paediatric population. The high incidence of conductive hearing loss in paediatric patients was attributed, in part, to the high incidence of serous otitis media which occurred in up to $80 \%$ of cases (Smith \& Canalis, 1989). Rosenberg, Schneider, and Cohen (1985) reviewed medical records of 102 adult patients with AIDS and found that although $71 \%$ of the patients had symptoms localised in the head and neck, none had otologic signs and symptoms. Similar results were reported by Marcusen and Sooy (1985) who also could not find any otologic findings in 165 AIDS infected patients they evaluated. Lalwani and Sooy (1992) maintain that otologic manifestations associated with HIV/AIDS do occur but are less common than other head and neck complaints. Methodological differences such as retrospective case reviews (Rosenberg et al., 1985) versus prospective evaluations of subjects (Marcusen \& Sooy, 1985) could have contributed to the contradictory findings.

The high incidence of hearing loss in the studied sample provides strong support for the view that audiologists should be involved in the assessment and management of patients with HIV/AIDS (Larson, 1998).

The type, degree, configuration, and symmetry of the hearing loss

Type of hearing loss
As can be seen in Figure 2, SNHL was the most commonly occurring type, while conductive hearing loss (CHL) was the least frequent. Of those with a SNHL 11 $(52 \%)$ were possibly cochlear, and $10(48 \%)$ were possibly retrocochlear; and $10(29 \%)$ had mixed hearing loss (MHL) as indicated in Figure 2. These results concur with the literature in that any type of hearing loss i.e. conductive, sensory/neural, or central hearing loss may be seen in HIV/AIDS (Chandrasekhar et al., 2000; Friedmann \& Noffsinger, 1998). However, the current results differ from the documented prevalence rates of types of hearing loss (Friedmann \& Noffsinger, 1998; Gold \& Tami,'1998; Lalwani \& Sooy, 1992). The most common otologic problems reported were serous otitis media and recurrent acute otitis media, and were predominantly related to Eustachian tube dysfunction implying that conductive hearing loss was the most common. In this study, CHL was the least common type of problem seen. There were slightly lower rates of occurrence of SNHL (between 20 and 50\%) reported by Gold and Tami (1998). The higher incidence in the current study could be related to sampling differences in that subjects with syphilis were excluded from some of the international studies.

\section{Degree of hearing loss}

Subjects had varying degrees of hearing loss as illustrated in Figure 3. Mild hearing loss (34\%) was most common, followed closely by the profound hearing impairment $(27 \%)$. Table 2 indicates that of the subjects

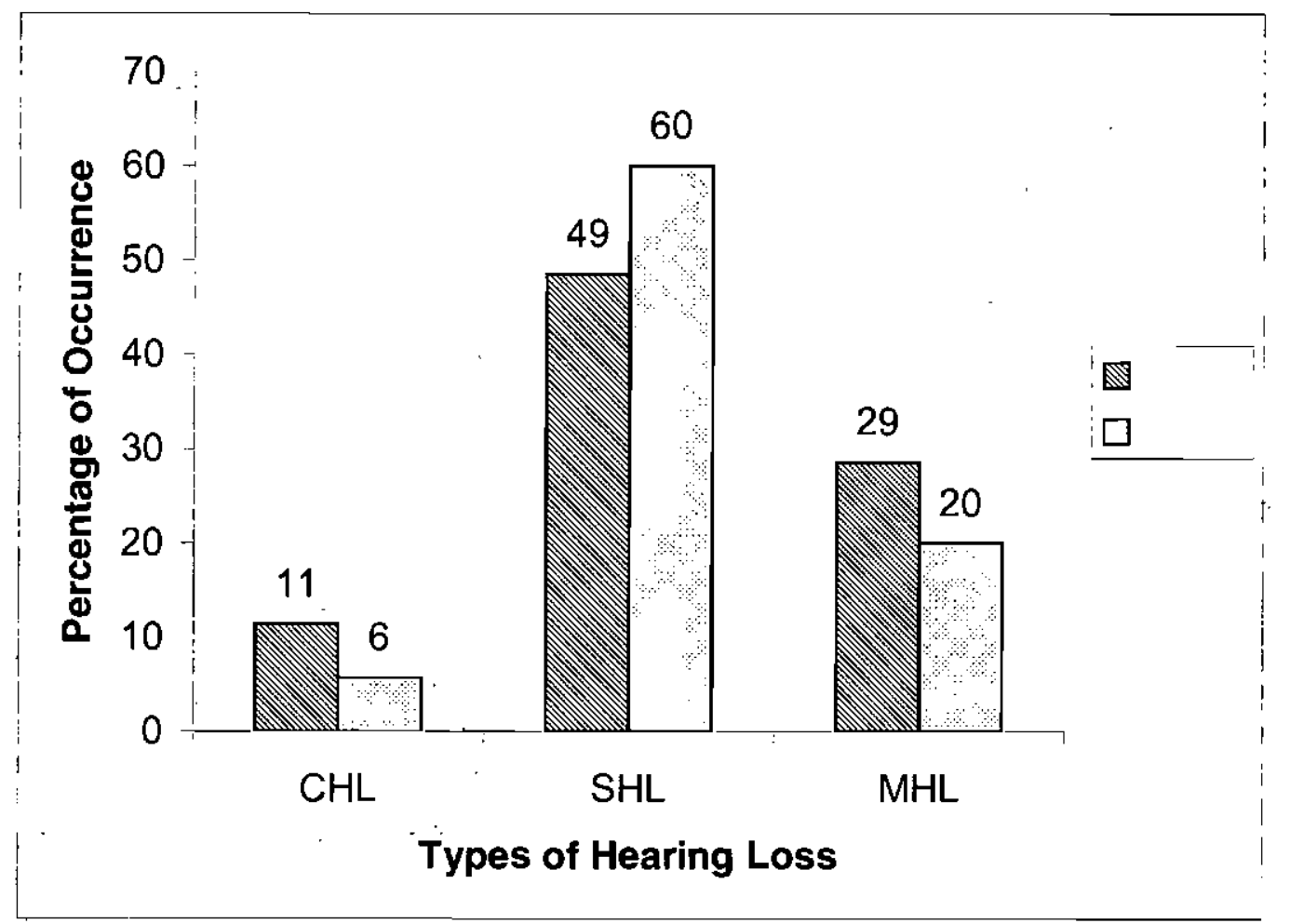

Figure 2: Types of hearing loss in the group of subjects with hearing loss ( $n=35$ )

Key: $\quad$ RPTA $=$ Right ear Pure Tone Audiometry

$\mathrm{CHL}=$ Conductive Hearing Loss

LPTA = Left ear Pure Tone Audiometry

SHL $=$ Sensorineural Hearing Loss

$\mathrm{MHL}=$ Mixed Hearing Loss 


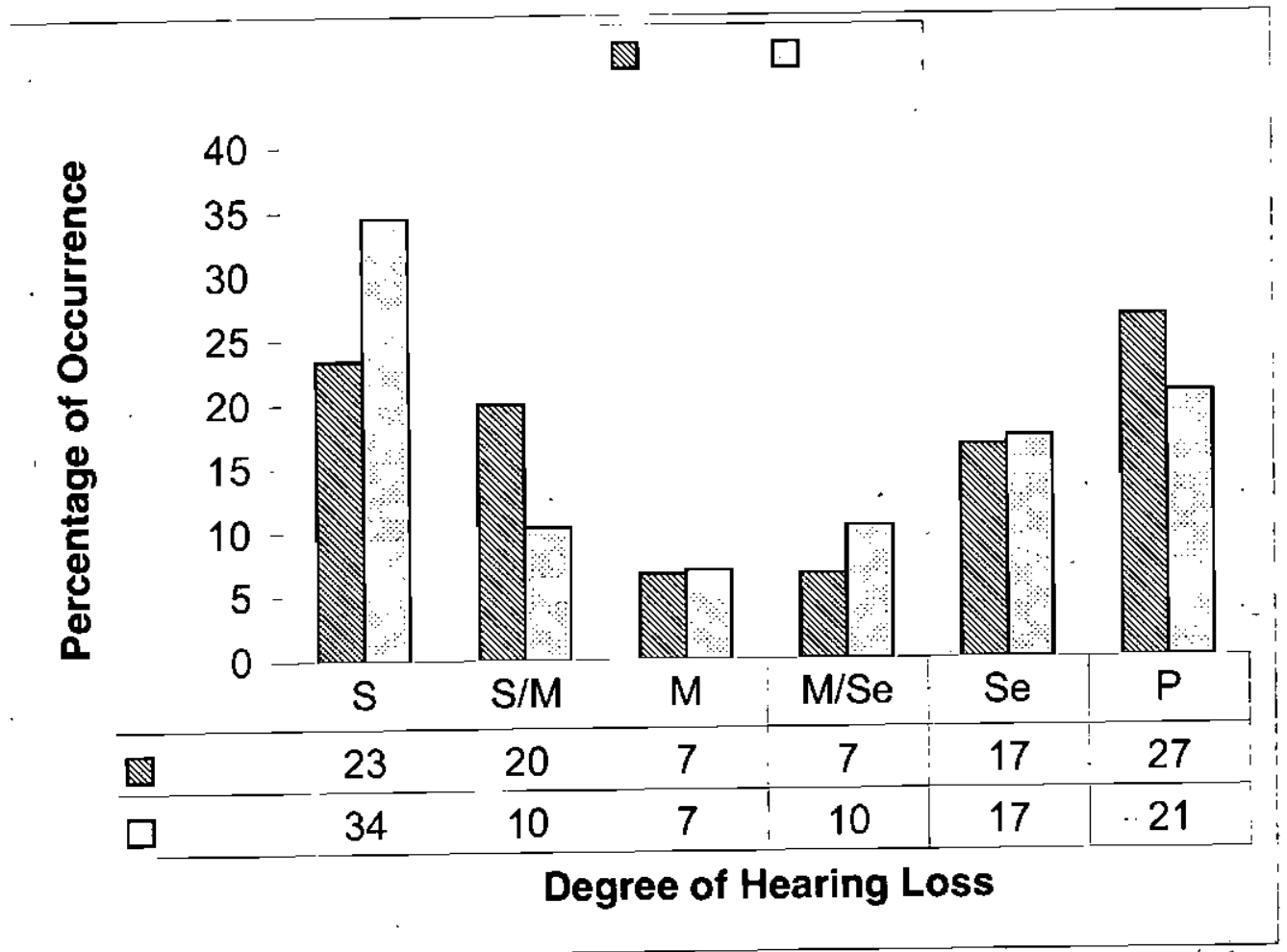

Figure 3: Degree of hearing loss in the subjects with hearing loss $(\mathrm{n}=35)$

Key: $\quad$ RPTA $=$ Right ear Pure Tone Audiometry

$$
\mathrm{S}=\text { Mild hearing loss }
$$

$\mathrm{M}=$ Moderate hearing loss

$\mathrm{Se}=$ Severe hearing loss

with SNHL, most of them (67\%) presented with a severe to profound hearing loss. These results differ from those reported in the literature where severity ranged from mild (Fuzani, 1999) to severe (Sooy, 1987), with little mention of profound hearing loss. Sooy (1987) reported that subjects presented with hearing losses greater than $25 \mathrm{~dB}$, typically ranging between 30 and $50 \mathrm{~dB} \mathrm{HL}$ at $8000 \mathrm{~Hz}$.

The degree of hearing loss reported in this study suggests that audiologic management of patients with HIV/AIDS should commence promptly so that early intervention can be instituted, thereby preventing further deterioration of hearing thresholds over time.

\section{Configuration of hearing loss}

No typical pattern of configuration of hearing loss could be established. Of the subjects with a hearing loss, only $14 \%$ presented with a sloping/high frequency hearing loss. The remaining $86 \%$ presented with flat and/or irregular audiograms, which related well to the possible causes of hearing loss (e.g., meningitis and otitis media which do not only affect high frequencies but low and mid frequencies as well) (Booth,
LPTA = Left ear Pure Tone Audiometry

$\mathrm{S} / \mathrm{M}=$ Mild to Moderate hearing loss

$\mathrm{M} / \mathrm{Se}=$ Moderate to Severe hearing loss

$\mathrm{P}=$ Profound hearing loss

1997). These results suggest that all frequencies may be affected equally or to varying degrees. Previous studies, however, e.g. Chandrasekhar et al. (2000), Gold and Tami (1998), and Lalwani and Sooy (1992) reported a sloping high frequency hearing loss, mostly SNHL. Aetiology of the hearing loss could be a contributory factor to the differences noted.

\section{Symmetry of hearing loss}

As can be seen from Table 3 , of the 35 subjects with hearing losses, $29 \%$ had unilateral hearing impairment while $71 \%$ presented with bilateral hearing loss, suggesting that hearing loss can be unilateral or bilateral in adults with HIV/AIDS. The high prevalence of bilateral hearing loss among subjects suggests that hearing impairment probably occurs more frequently and with greater severity than anticipated in the patients with HIV/AIDS. Bilateral hearing loss has been reported to

Table 2. Type of onset of hearing loss in subjects with hearing loss $(n=35)$

\begin{tabular}{|l|l|}
\hline Sudden Onset & Gradual/progressive Onset \\
\hline Total $=16$ & Total $=19$ \\
\hline$>13(81 \%)$ - severe to profound SNHL & $>2(10 \%)$ severe SNHL \\
$>3$ mild-moderate hearing loss & $>7(37 \%)$ mild-moderate SNHL \\
& $>10(53 \%)$ conductive and mixed \\
\hline
\end{tabular}


impact more severely on communication than unilateral hearing loss, and therefore requires prompt diagnosis and management (Katz, 1994; Silman \& Silverman, 1991). Early intervention in terms of medical management and/or amplification would enhance patients' communication abilities, and faciltate compliance with any verbally prescribed medical treatment. Hence, enhanced communication could potentially improve not only the social, academic, and vocational quality of the patients' life, but also their general health.

The relationship between hearing loss and the progressive stages of HIV/AIDS

As illustrated in Figure 4, there was a trend towards an increase in the number of occurrences of SNHL from stage 1 (asymptomatic) to stage 3 (fullblown AIDS), but there was no definitive relationship to the $3 \mathrm{CDC}$ categories for $\mathrm{CHL}$ and $\mathrm{MHL}$. These findings are supported by evidence which suggests a relationship between audiological manifestations and the progression of the HIV/AIDS disease (Birchall et al., 1992; Chandrasekhar et al., 2000; Lalwäni \& Sooy 1992).

The increase in the occurrence of SNHL with advanced stages of the disease in the current study may be attributed to the progressive decline in the immunologic status which increases susceptibility to the neurotropic nature of the disease and to opportunistic infections, which have been found to cause hearing loss (Friedmann \& Arnold, 1993; Real et al., 1987; Schuknecht, 1993).

\section{Type of onset of hearing symptoms}

As indicated in Table 2, similar numbers of subjects presented with sudden and with gradual onset of hearing loss. Several studies have reported sudden onset of SNHL in patients with HIV/AIDS (Real et al., 1987;
Timon \& Walsh, 1989). Smith and Canalis (1989) reported that SNHL can occasionally be of a sudden onset but is commonly rapidly progressive. Chandrasekhar et al. (2000) also reported similar findings with $3 \%$ presenting with sudden onset, $21 \%$ with gradual onset, while the largest number demonstrated intermittent onset.

\section{Type of onset of SNHL and its relationship to degree of the hearing loss}

As further indicated in Table 2, sudden onset of hearing loss occurred most frequently in subjects who presented with severe to profound SNHL, while gradual onset was mostly found in subjects who presented with conductive and/or mixed hearing losses. Real et al. (1987) suggested that sudden SNHL (temporary or permanent) was frequently caused by viral agents, in as many as $33 \%$ of cases.

The relationship between HIV/AIDS signs and symptoms and the nature of the hearing loss

Detailed descriptive analysis of the audiologic evaluation results together with the documented case history information where medical diagnoses had been confirmed by Ear, Nose and Throat Specialists revealed the following:

$>$ Patients who presented with SNHL had documented medical histories of meningitis (aseptic; cryptococcal; and viral); infections (syphilis and otosyphilis; encephalitis); and histories of ototoxic medication used in the treatment of TB and other opportunistic infections. Three patients had possible noiseinduced hearing loss due to industrial noise exposure.

$>$ Patients who presented with CHL and MHL

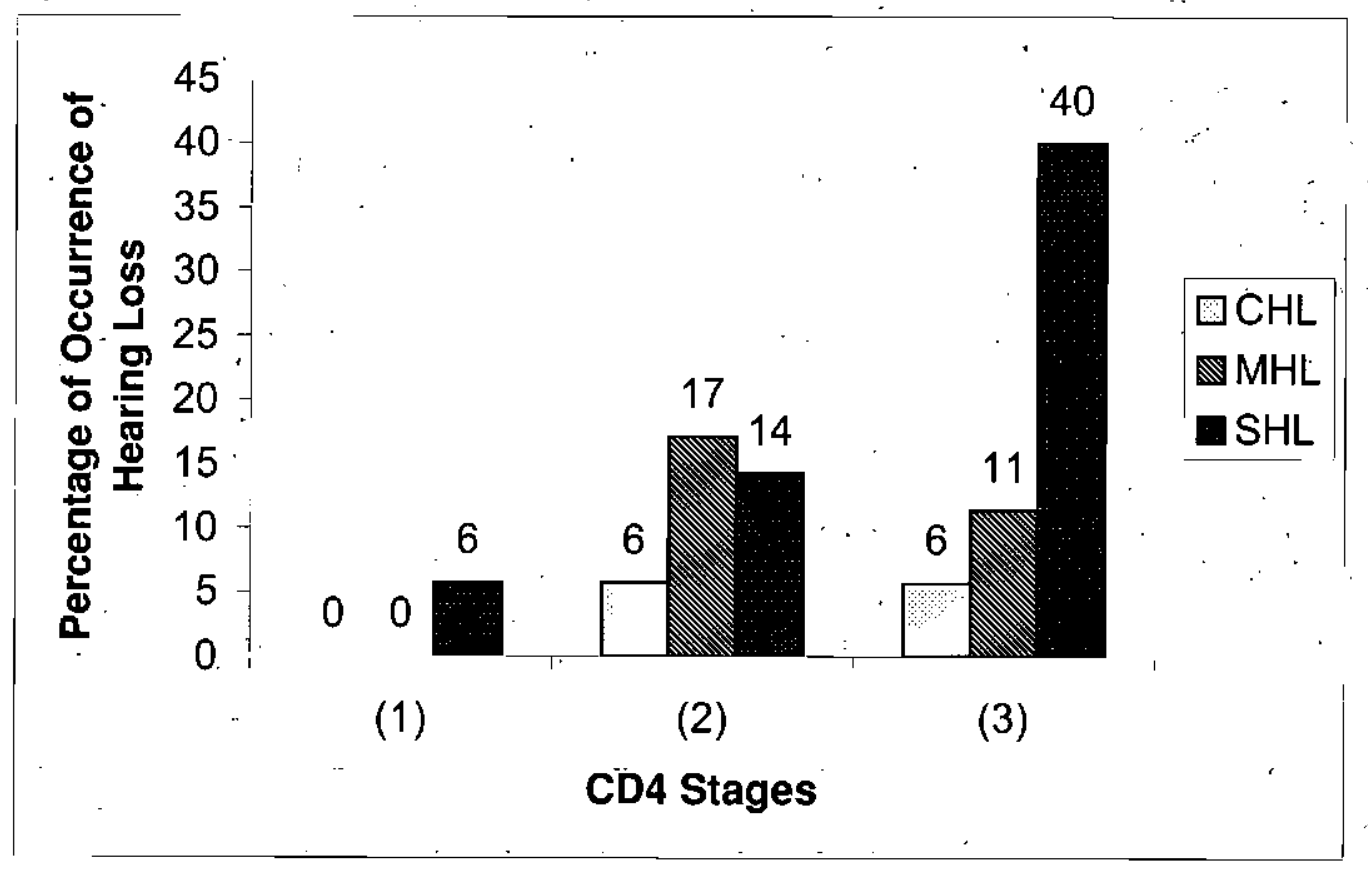

Figure 4: Hearing loss and its relationship to the CD4+ count in the subjects with hearing. loss $(\mathrm{n}=35)$

Key: $\quad \mathrm{CHL}=$ Conductive Hearing Loss

SHL $=$ Sensorineural Hearing Loss

2 = stage 2 of HIV/AIDS (Symptomatic)
MHL $=$ Mixed Hearing Loss

$1=$ stage 1 of HIV/AIDS (Asymptomatic)

$3=$ stage 3 of HIV/AIDS (AIDS) 
had a history of chronic suppurative otitis media, and otitis media with effusion.

The above results are consistent with the welldocumented causes of hearing loss in the population with HIV/AIDS (Friedmann \& Amold, 1993; Smith \& Canalis, 1989). It has been reported that decreased cellmediated immunity, - recurrent viral- infections, nonmalignant lymphoid hyperplasia of the adenoids, nasopharyngeal tumours; sinusitis, or allergic autoimmune reaction to HIV can all lead to poor Eustachian tube function and middle ear effusions (Friedmann \& Arnold, 1993; Gold \& Tami, 1998; Lalwani \& Sooy, 1992). Chandrasekhar et al. (2000) reported that $23 \%$ of adults with HIV presented with otitis media which is highly uncommon in adults who are HIV-negative, and thus suggest that conductive hearing loss can be expected as a presenting problem in HIVinfected patients.

The causes of SNHL (which involve the Central Nervous System (CNS) and the sensory end organs) in HIV/AIDS include cranial neuropathy due to meningitis (aseptic, cryptococcal, and viral) or lymphoma; viruses (cytomegalovirus; hepatitis $\mathrm{B}$; herpes simplex and syphilis -otosyphilis and neurosyphilis; herpes zoster; and toxoplasma) which are conditions reported to be more common in patients with HIV than in healthy individuals; ototoxic drugs used in the treatment of opportunistic infections and neoplasms; and intracranial events, such as encephalitis and haemorrhage (Bankaitis \& Schountz, 1998; Booth, 1997; Friedmann \& Arnold, 1993; Larson, 1998; Real et al., 1987; Schuknecht, 1993; Smith \& Canalis, 1989).

In this study, meningitis and syphilis were the two major possible causes of SNHL with encephalitis and ototoxicity being minor causes. The three types of meningitis (aseptic, cryptococcal, and viral) reported, all have an effect on the auditory system (Schuknecht, 1993). Cryptococcal meningitis is an opportunistic infection that has its primary focus in the lung with spread mainly to the meninges (Schuknecht, 1993). This infection causes similar tissue damage both in people with and without HIV infection, with the exception that

Table 3: Summary of case history data for subjects with hearing loss $(n=35) \quad$..

\begin{tabular}{|c|c|c|c|}
\hline Factor & Sub-Category & Number & Percentage \\
\hline CD4+ Count $\left(/ \mathrm{mm}^{3}\right)$ & $\begin{array}{l}\text { Asymptomatic (Stage 1) }>500 / \mathrm{mm}^{3} \\
\text { Symptomatic (Stage 2) } 200-499 / \mathrm{mm}^{3} \\
\text { AIDS (Stage 3) }<200 / \mathrm{mm}^{3}\end{array}$ & $\begin{array}{l}3 \\
13 \\
19\end{array}$ & $\begin{array}{l}9 . \\
37 \\
54\end{array}$ \\
\hline Type of hearing loss & $\begin{array}{l}\text { Conductive Hearing Loss } \\
\text { Sensorineural Hearing Loss } \\
\text { Mixed Hearing Loss }\end{array}$ & $\begin{array}{l}4 \\
21 \\
10\end{array}$ & $\begin{array}{l}11 \\
60 \\
29\end{array}$ \\
\hline $\begin{array}{l}\text { Type of onset of } \\
\text { hearing loss }\end{array}$ & $\begin{array}{l}\text { Sudden } \\
\text { Gradual }\end{array}$ & $\begin{array}{l}16 \\
19 .\end{array}$ & $\begin{array}{l}46 \\
54\end{array}$ \\
\hline $\begin{array}{l}\text { Symmetry of hearing } \\
\text { loss }\end{array}$ & $\begin{array}{l}\text { Unilateral } \\
\text { Bilateral }\end{array}$ & $\begin{array}{l}10 \\
25\end{array}$ & $\begin{array}{l}29 \\
71\end{array}$ \\
\hline $\begin{array}{lll}\text { Possible aetiology of } \\
\text { hearing loss * }\end{array}$ & $\begin{array}{l}\text { Meningitis } \\
\text { Oto/syphilis } \\
\text { Otitis Media } \\
\text { Encephalitis } \\
\text { TB Treatment }\end{array}$ & $\begin{array}{l}9 \\
13 \\
14 \\
1 \\
2\end{array}$ & $\begin{array}{l}26 \\
37 \\
40 \\
3 \\
9\end{array}$ \\
\hline $\begin{array}{l}\text { Possible site of lesion } \\
\text { of SNHL }(n=21)\end{array}$ & $\begin{array}{l}\text { Cochlear } \\
\text { '́atrocochlear }\end{array}$ & $\begin{array}{l}11 \\
10\end{array}$ & $\begin{array}{l}52 \\
48\end{array}$ \\
\hline $\begin{array}{l}\text { Degree of SNHL } \\
(n=21)\end{array}$ & $\begin{array}{l}\text { Mild- Moderate } \\
\text { Severe-Profound }\end{array}$ & $\begin{array}{l}7 \\
14\end{array}$ & $\begin{array}{l}33 \\
67\end{array}$ \\
\hline Tinnitus & $\begin{array}{l}\text { Present } \\
\text { Absent }\end{array}$ & $\begin{array}{l}16 \\
19\end{array}$ & $\begin{array}{l}46 \\
54\end{array}$ \\
\hline Vertigo & $\begin{array}{l}\text { Present } \\
\text { Absent }\end{array}$ & $\begin{array}{l}9 \\
26\end{array}$ & $\begin{array}{l}26 \\
74\end{array}$ \\
\hline $\begin{array}{c}\text { Noise Exposure } \\
\vdots\end{array}$ & $\begin{array}{l}\text { Present } \\
\text { Absent }\end{array}$ & $\begin{array}{l}6 \\
29\end{array}$ & $\begin{array}{l}17 \\
83\end{array}$ \\
\hline
\end{tabular}

Note: *\% Scores do not add up to $100 \%$ as some subjects presented with more than one possible aetiological factor 
in people with HIV, the damage tends to be more extensive and destructive (Larson, 1998). Booth (1997) reports cryptococcal meningitis as being increasingly associated with sudden onset SNHL with the incidence as high as $27 \%$. The hearing loss is reported to be mostly retrocochlear in nature. In the current study, of the 3 subjects with cryptococcal meningitis, one subject had a possible cochlear site of lesion, while the other two subjects had possible retrocochlear lesions. Real et al. (1987) reported that the organism in cryptococcal meningitis has been found in both the cochlear and vestibular nerves, and in the end organs, with severe damage to the organ of Corti. They further report that neuronal loss with good hair cell preservation can also be found. Thus they suggested that hearing loss due to cryptococcal meningitis could be either cochlear or retrocochlear in nature.

Syphilis and otosyphilis have been linked to sudden or gradual onset of SNHL (Schuknecht, 1993). Research has suggested that otosyphilis affects the cochlear (Booth, 1997; Friedmann \& Arnold, 1993; Smith \& Canalis, 1989). In contrast, the current study had four patients with possible retrocochlear lesions. It could be speculated that such a finding was possibly related to difficulty in diagnosing otosyphilis (Friedmann \& Arnold, 1993); which might lead to an incorrect diagnosis, especially if a differential diagnosis has not been done to exclude other systemic processes that occur in the HIV/AIDS population. Retrocochlear lesions may also be possible since HIV changes the course of syphilis by hastening the development of neurosyphilis with resultant neural hearing loss (Smith \& Canalis, 1989).

Ototoxicity can occur in this population since the patients' drug regimen often involves potentially ototoxic medications. However, this issue requires more research as Bankaitis and Schountz (1998) reported that experimental antiretroviral drugs (with undocumented or unknown side effects) could contribute to hearing loss, while Chandrasekhar et al. (2000) reported no correlation between sensorineural hearing loss and routine medications.

\section{Medical histories of normal hearing subjects vs. subjects with hearing losses:}

Of the total of 150 subjects evaluated, 115 subjects presented with normal hearing thresholds. In Phase IV of the study, it became evident that the major differentiating factor between the two groups (normal hearing group and the hearing impaired group) was the presence of opportunistic infections. Subjects with normal hearing had no opportunistic infections and other possible causes of hearing loss, except in $12 \%$ of the subjects.

There was, however, strong evidence suggesting that hearing loss, in this study, was probably due to opportunistic infections and their treatment rather than from HIV/AIDS alone. Of the $23 \%$ of subjects with hearing loss, almost all presented with a history of opportunistic infections and other aetiological factors associated with hearing loss in patients with HIV/AIDS. Hence, the hearing loss in HIV/AIDS subjects may not be solely attributable to HIV/AIDS but to a combination of factors.

\section{CONCLUSION}

Numerous internationally published studies have demonstrated a correlation between hearing loss and HIV/AIDS (Bankaitis, 1996; Birchall et al., 1992; Chandrasekhar et al., 2000; Gold \& Tami, 1998; Sooy, 1987). Findings from the present exploratory-descriptive study conducted on a local South African sample also revealed a relationship between HIV/AIDS and auditory function. The estimated prevalence of hearing loss among adults attending an HIV/AIDS clinic in a government hospital in. Gauteng was around $23 \%$. The hearing loss occurred at any stage of the disease with varying degrees of severity and types. In addition, it is suggested that a diagnosis of HIV/AIDS be suspected if a patient presents with a sudden hearing loss, with no clear aetiology, as it could be the first symptom in some undiagnosed HIV/AIDS patients.

Results from the present study have the potential to contribute toward enhancing audiological assessment and management of patients infected with this virus, particularly in the current era of financial constraints across services in provincial hospitals. However, these results need to be considered in relation to issues identified in the project's research design and analysis.

By ensuring that appropriate management in the form of correct hearing aid fitting where progression of the hearing loss is known or suspected, regular rechecks of hearing status for possible adjustment of hearing aid settings so as to ensure maximum benefit from amplification, and visual training where hearing aids are of no or little benefit to patients, audiologists will be contributing enormously towards providing efficacious care to patients with HIV/AIDS.

In conclusion, the results from the present study suggest that the audiologic presentation of patients with HIV/AIDS is consistent with their immunocompromised status. Susceptibility to opportunistic infections increases chances of quantifiable audiological sequelae.

\section{REFERENCES}

Bankaitis, A.E. (1996). Audiological changes attributable to HIV. Audiology Today, 8(6), 1416.

Bankaitis, A.F., \& Keith, R.W. (1995). Audiologic changes associated with HIV infection, Ear Nose and Throat Journal, 74, 353-359.

Bankaitis, A.E., \& Schountz, T. (1998). HIV-related ototoxicity. Seminars in Hearing, 19, 155-163.

Birchall, M., Wight, R., French, P., Cockbain, Z., \& Smith, S. (1992). Auditory function in patients infected with the human immunodeficiency virus. Clinical Otolaryngology, 17, 117-121.

Booth, J.B. (1997). Scott-Brown's Otolaryngology: Otology. $\left(6^{\text {th }}\right.$ Ed), Boston: ButterworthHeinemann.

Chandrasekhar, S.S., Connelly, P.E., Brahmbhatt, S.S., Chetan, B.S., Shah, S., Kloser, P.C., \& Baredes, S. (2000). Otólogic and audiologic evaluation of human immunodeficiency virusinfected patients. American Journal of Otolaryngology, $2 I(1), 1-9$. 
Crewe, M. (1999, November). AIDS, activism and the role of the universities. Paper presented at the conference of the social, demographic, and development impact of AIDS: Commonwealth universities respond, Durban, South Africa.

Darnstadt, G. L., \& Harris, J.P. (1989). Luetic hearing loss: clinical presentation, diagnosis, and treatment. American Journal of Otolaryngology, 10:410.

Department of Health. (2000). HIV/AIDS/STD strategic plan for South Africa 2000-2005. RSA.

Friedmann, I., \& Arnold, W. (1993). Pathology of the ear. London: Churchill Livingstone.

Friedman, J.L., \& Noffsinger, D. (1998). Hearing loss associated with HIV/AIDS: social, cultural, and political issues. Seminars in Hearing, 19, 205214.

Fuzani, P. (1999). The type, degree and prevalence of hearing loss in black female HIV positive patients at various clinical stages of infection in South Africa. Undergraduate unpublished report, University of the Witwatersrand, Johannesburg.

Gold, S., \& Tami, T.A. (1998). Otolaryngological manifestations of HIV/AIDS. Seminars in Hearing, 19, 165-175.

Hall, J.W. (1992). Handbook of auditory evoked responses. Boston: Allyn \& Bacon.

Hood, L.J. (1998). Clinical applications of the auditory brainstem response. San Diego: Singular Publishing.

Jacobson, J.T., \& Northern, J.L. (1990). Diagnostic audiology. Boston: Allyn and Bacon.

Katz, J. (1994). Handbook of clinical audiology. Baltimore: Williams \& Wilkins.

Kemp, R.J., \& Roeser, R.J. (1998). Infection control for audiologists. Seminars in Hearing, 19(2), 195203.

Lalwani, A.K., \& Sooy, C.D. (1992). Otologic and neurologic manifestations of ' acquired immunodeficiency syndrome. The Otolaryngological Clinics of North America, 25(6), 1183-1198.

Larson, C.R. (1998). HIV-I and communication disorders: What speech and hearing professionals need to know. London: Singular Publishing Inc.

Marcusen, D.C., \& Sooy, C.D. (1985). Otolaryngologic and head and neck manifestations of acquired immunodeficiency syndrome (AIDS). Laryngoscope, 95, 401-405.
Matkin, N.D., Diefendorf, A.O., \& Erenberg, A. (1998). Children: HIV/AIDS and hearing loss. Seminars in Hearing, 19, 143-153.

McCall, R.B. (1990). Fundamental statistics for behavioral sciences $\left(4^{\text {th }}\right.$ Ed). New York.

Noffsinger, D., \& Friedman, J. (1996). Audiology and the person with hearing loss associated with HIV/AIDS. Audiology Today, 8(6), 12-13.

Real, R., Thomas, M., \& Gerwins, J.M. (1987). Sudden hearing loss and acquired immunodeficiency syndrome. Otolaryngology Head and Neck Surgery, 97, 4099-4120.

Regensberg, L., \& Maartens, G. (1999). Antiretroviral therapy in adults. Modern Medicine of South Africa, 30-38.

Rosenberg, R.A., Schneider, K.L., \& Cohen, N.L. (1985). Head and neck presentations of acquired immunodeficiency syndrome. Otolaryngology Head Neck Surgery, 93, 700-705.

Schuknecht, H.F. (1993). Pathology of the ear ( $\left.2^{\text {nd }} \mathrm{Ed}\right)$. London: Lea \& Febiger.

Silman, S., \& Silverman, C.A. (1991). Auditory diagnosis: Principles and applications. San Diego: Academic Press.

Smith, M.E., \& Canalis, R.F. (1989). Otologic manifestations of AIDS: The otosyphilis connection. Laryngoscope, 99, 365-372.

Sooy, C.D. (1987). The impact of AIDS on otolaryngology - head and neck surgery. Advances in Otolaryngological Head \& Neck Surgery, 1, 1-28.

Spehlmann, R. (1985). Evoked potential primer: Visual, auditory, and somatosensory evoked potentials in clinical diagnosis. Boston: Butterworth.

Timon, C.I., \& Walsh, M.A.' (1989). Sudden hearing loss as a presentation of HIV infection. Journal of Laryngology and Otology, 103, 1071-1072.

Tshabalala-Msimang, M.E. (1999). Overview of the national HIV sero-prevalence survey of women attending public antenatal clinics in South Africa: National HIV/AIDS Statistics/ $13^{\text {th }}$ International Aids Conference, South African Department of Health, RSA

Wiley, T.L., \& Fowler, C.G. (1997). Acoustic immittance measures in clinical audiology. San Diego: Singular Publishing.

Wilson, J.W., Jones, B., \& Fridjhon, P. (1998). Use of the NAL-AB wordlists as a South African English speech discrimination test. The South African Journal of Communication Disorders, 45. 